\title{
Vascular Injury by Arterial Hypertension in Anti-Phospholipid Antibody Syndrome
}

\author{
Paola Mesiano $^{1^{*}}$, Carlo Massara ${ }^{1}$, Cristiana Rollino ${ }^{1}$, Marco Borca ${ }^{1}$ and Dario Roccatello ${ }^{1,2}$
}

${ }^{1}$ Nephrology and Dialysis Unit, Italy

${ }^{2}$ Center of Research on Immunopathology and Documentation on Rare Diseases, St. G. Bosco Hospital and University of Turin, Turin, Italy

*Corresponding author: Paola Mesiano, M.D Department of Nephrology and Dialysis, St. G. Bosco Hospital, Turin, Italy, Tel: +39-0112402889; E-mail: paola.mesiano@gmail.com

Rec date: Nov 27, 2014; Acc date: Dec 09, 2014; Pub date: Dec 11, 2014

Copyright: $\odot 2015$ Mesiano P, et al. This is an open-access article distributed under the terms of the Creative Commons Attribution License, which permits unrestricted use, distribution, and reproduction in any medium, provided the original author and source are credited.

Keywords: Antiphospholipid syndrome; Erythematosus; histological examination of the mediastinal lymph nodes were all Microangiopathy; Renal Artery Stenosis normal.

\section{Introduction}

Antiphospholipid Syndrome (APS) is defined as the presence of recurrent arterial or venous thrombosis and/or pregnancy morbidity and persistently elevated levels of antiphospholipid antibodies (aPLs) [1]. APS is classified as being primary if autoimmunity is negative, and secondary when it occurs in the course of an autoimmune disease, most often systemic lupus erythematosus [2]. In the original description of the syndrome made by Hughes, arterial hypertension was a common feature that was often associated with livedo reticularis [3]. Thrombosis in vessels of all sizes of the renal vasculature may be responsible for a wide range of renal diseases including systemic hypertension, renal artery stenosis, renal infarction, APS nephropathy, thrombotic microangiopathy and renal vein thrombosis [4]. The prevalence of hypertension (which ranges from mild to severe) in APS is significantly higher in the presence of renal involvement $(57.1 \%$ versus $22.6 \%$ in Sinico's cohort [5]), and the kidney may be considered both the 'culprit' and the 'victim' of hypertension in APS, as occurs in other forms of hypertension. We present a case of primary APS with multiple organ involvement, kidney disease and newly diagnosed arterial hypertension, and we discuss the possible mechanisms and management of hypertension in the course of this rare disease.

\section{Case Presentation}

At the end of July 2013, a 44-year-old man complaining of left flank pain and progressive dyspnea was admitted to the Emergency Department of our Hospital with computed tomography evidence of pulmonary embolism, multiple pulmonary infarcts, hilar adenopathy and splenic infarction. Medical history was unremarkable except for smoking since the age of 20, asthenia and weight loss over the previous six months. Outpatient empirical treatment with ceftriaxone and azithromycin had been previously prescribed on the basis of a chest $\mathrm{x}$ ray taken at the beginning of July, which had shown left lower lobe lung consolidation and hilar enlargement.

At admission the patient was in good general condition, weight 74 $\mathrm{Kg}$ (usual weight $80 \mathrm{Kg}$ ), height $185 \mathrm{~cm}$, Body Mass Index 21.6, arterial blood pressure $168 / 102 \mathrm{mmHg}$ bilaterally, pulse was regular, heart rate 110 beats per minute, respiratory rate 16 per minute, peripheral oxygen saturation $100 \%$. Physical examination was unremarkable. During hospitalisation, grade 1-2 arterial hypertension was confirmed, according to the 2013 European Society of Hypertension Guidelines classification. Bronchoscopy, bronchoalveolar lavage fluid and
One week after admission the patient was transferred to our Nephrology Ward. Serum creatinine was $1.5 \mathrm{mg} / \mathrm{dL}$, and neither micro albuminuria nor urinary sediment activity was observed. Other laboratory investigations revealed microcytic anemia (Haemoglobin $8.4 \mathrm{~g} / \mathrm{dL}$, mean corpuscular volume $66.7 \mathrm{fL}$ ) with low transferrin saturation (8\%) and normal serum ferritin (59 $\mathrm{ng} / \mathrm{mL})$, thrombocytopenia (platelet count $67,000 / \mathrm{uL}$ ), positive plasma DDimer test $(2.29 \mathrm{mcg} / \mathrm{ml}$, normal value $<0.5 \mathrm{mcg} / \mathrm{ml})$ and prolonged partial thromboplastin time $(66.7 \mathrm{sec}$, ratio 1.96$)$. There were no other signs of haemolysis. Lipid profile showed low high-density lipoprotein cholesterol $(29 \mathrm{mg} / \mathrm{dl})$ with elevated low-density lipoprotein (149 $\mathrm{mg} / \mathrm{dl})$ and normal triglyceride levels $(130 \mathrm{mg} / \mathrm{dl})$. Glucose, uric acid levels, TSH and procalcitonin levels were normal. Anti-dsDNA and anti-ENA were also negative, with C3 hypocomplementemia (77-81 $\mathrm{mg} / \mathrm{dl}$, nv 90-180 mg/dl), positive low titre (1:40) antinuclear antibodies and positive atypical p-ANCA (1:320). Ig levels were within the normal range.

Silica clotting time and dilute Russell's viper venom (screen, mixing, and confirmatory) test indicated the presence of Lupus Anticoagulant (LA). Anti-b2 glycoprotein-I (antibeta2GPI) antibodies of IgM isotype were present $(31 \mathrm{U} / \mathrm{ml})$, with negative $\operatorname{IgG}(5 \mathrm{U} / \mathrm{ml})$. Anticardiolipin $(\mathrm{aCL})$ antibodies were present in tests carried out 16 weeks apart (IgG $20 \mathrm{GPL} / \mathrm{ml}$, IgM $23 \mathrm{MPL} / \mathrm{ml}$ ), though with normal antib2GPI IgG and IgM. LA was not used for confirmation due to concomitant vitamin $\mathrm{k}$ antagonist treatment. Functional testing for protein $\mathrm{C}$ was normal, with decreased levels of free protein S (44\%). Serum homocysteine levels were above the upper reference limit (16 microg/dl), with methylene tetra hydrofolate reductase C677T homozygous genotype and wild-type Factor V Leiden and Prothrombin genotype. A diagnosis of primary Antiphospholipid Syndrome was made. Renal ultrasound and Doppler showed normal kidneys and normal renal resistive index, in the absence of renal artery stenosis. Electrocardiogram was normal. Echocardiogram showed an increased left ventricular mass $\left(127 \mathrm{~g} / \mathrm{m}^{2}\right)$, normal ejection fraction, left atrium area of $21.6 \mathrm{~mm} / \mathrm{m}^{2}$, moderate mitral valve stenosis (area $1.57 \mathrm{~cm}^{2}$ ) with severe regurgitation (effective regurgitant orifice $0.40 \mathrm{~cm}^{2}$ ), while pulmonary artery pressure was $60 \mathrm{mmHg}$. Blood pressure control was easily achieved with amlodipine $5 \mathrm{mg}$ and ramipril $5 \mathrm{mg}$. The patient underwent standard treatment for thrombosis in APS with anticoagulants (low molecular weight heparin, followed by warfarin as of August, 2013, with international normalized ratio target between2.0-3.0). Due to the severity of presentation, treatment with three consecutive daily infusions of Intravenous Immunoglobulins (IVIG) at a monthly dose of $0.4 / \mathrm{kg} /$ day for three months was started in 
the middle of August, combined with hydroxychloroquine $200 \mathrm{mg} /$ day, based on our previous experience in APS [6].

Platelet count and haemoglobin increased progressively once the treatment was started, and after one month of hospitalisation the patient was discharged in good clinical condition. Outpatient followup visits from September to December, 2013, showed normalisation of platelet and red blood cell counts, persistence of the mild decrease in renal function (serum creatinine $1.3 \mathrm{mg} / \mathrm{dL}$, CKD-EPI Creatinine Equation $66 \mathrm{~mL} / \mathrm{min} / 1.73 \mathrm{~m}^{2}$ ) with no signs of urinary activity. Blood pressure control was optimal $<140 / 90 \mathrm{mmHg}$. Dual Energy computed tomography performed at the end of September 2013, showed partial resolution of the pulmonary infarctions and a reduction of the hilar adenopathy.

In January, 2014, the patient underwent minimally invasive heart surgery for mitral valve replacement with a mechanical prosthesis (29 mm, St. Jude Medical, Inc. St. Paul, MN, USA), without complications. He was discharged with a serum creatinine level of $1.27 \mathrm{mg} / \mathrm{dL}$ and good blood pressure control.

\section{Discussion}

On the basis of classification criteria, our patient was diagnosed with APS since he presented two documented thrombotic events associated with combined aPLs positivity, which was confirmed on two occasions. Associated, non-criteria clinical manifestations included heart valve disease and thrombocytopenia.

As far as renal manifestations are concerned, at presentation our patient displayed mild renal insufficiency with neither overt proteinuria nor signs of urinary activity, which could not be classified as pre-existing since previous renal function was unknown. Moreover, he was found to have grade2 arterial hypertension, which is sometimes the only clinical sign suggestive of possible renal involvement in APS [7]. The kidney, a target organ in APS, may, in turn, play a major role in the pathogenesis of hypertension in the course of APS. Renal artery stenosis, which is potentially responsible for renovascular hypertension, was ruled out by Doppler sonography. In an analysis of 16 patients with primary APS, Nochy proposed that systemic hypertension could be caused by the intrarenal vascular lesions found in APS nephropathy via stimulation of the renin angiotensinaldosterone system [7]. However, since renal biopsy was not performed on our patient due to the concomitant and mandatory anticoagulant treatment and the persistent thrombocytopenia, the pathological features of renal disease remained undefined. Furthermore, on the basis of the clinical presentation, we were not able to determine whether renal failure was a manifestation of APS (APS nephropathy) or if it was caused by nephroangio sclerosis secondary to hypertension. This latter hypothesis cannot be definitively ruled out because echocardiogram showed mild IVS, consistent with a possible previous hypertensive condition. Hypertension in APS is often associated with renal involvement, but other non renal risk factors may be implicated (obesity, previous corticosteroid treatment in secondary APS, dyslipidemia, accelerated atherosclerosis).
During hospitalisation, once renal artery stenosis had been ruled out, blood pressure control was easily obtained in our patient by using combination therapy with calcium channel blockers and ACEinhibitors. Management of hypertension in these patients can be difficult, mainly in hypertensive emergencies. In our patient, inhibition of the renin-angiotensin-aldosterone system with aceinhibitors, associated with calcium channel blockers (as per international guidelines on hypertension for combination treatment) provided good blood pressure control.

\section{Conclusions}

Hypertension can be associated with APS and has been reported as a strong risk factor for thrombosis in aPL carriers [8]. Hypertension is known to be a cause of the progression of renal failure and is the second leading cause of end stage renal disease in the U.S (U.S. Renal Data System 2010 Annual Data Report), therefore tight control of blood pressure is an important goal in these patients in whom hypertension and kidney damage frequently co-exist. APS may be considered a model for accelerated arterial disease [9], and preventing cardiovascular disease in these patients is mandatory for both the patient (smoking cessation, regular physical activity, avoiding overweight) and the physician (correct management of hypertension, dyslipidemia and diabetes).

\section{References}

1. Miyakis S, Lockshin MD, Atsumi T, Branch DW, Brey RL, et al. (2006) International consensus statement on an update of the classification criteria for definite antiphospholipid syndrome (APS). J Thromb Haemost 4: 295-306.

2. Asherson RA, Khamashta MA, Ordi-Ros J, Derksen RH, Machin SJ, et al. (1989) The "primary" antiphospholipid syndrome: major clinical and serological features. Medicine (Baltimore) 68: 366-374.

3. Hughes GR (1984) The Prosser-White oration 1983. Connective tissue disease and the skin Clin Exp Dermatol 9: 535-544.

4. Sciascia S, Cuadrado MJ, Khamashta M, Roccatello D (2014) Renal involvement in antiphospholipid syndrome. Nat Rev Nephrol 10: 279-289.

5. Sinico RA, Cavazzana I, Nuzzo M, Vianelli M, Napodano P, et al. (2010) Renal involvement in primary antiphospholipid syndrome: retrospective analysis of 160 patients. Clin J Am Soc Nephrol 5: 1211-1217.

6. Sciascia S, Giachino O, Roccatello D (2012) Prevention of thrombosis relapse inantiphospholipid syndrome patients refractory to conventional therapy using intravenous immunoglobulin. Clin Exp Rheumatol 30: 409-413.

7. Nochy D, Daugas E, Droz D, Beaufils H, Grünfeld JP, et al. (1999) The intrarenal vascular lesions associated with primary antiphospholipid syndrome. J Am Soc Nephrol 10: 507-518.

8. Ruffatti A, Del Ross T, Ciprian M, Bertero MT, Sciascia S (2011) Risk factors for a first thrombotic event in antiphospholipid antibody carriers: a prospective multicentre follow-up study. Ann Rheum Dis 70: 1083-1086.

9. George J, Shoenfeld Y (1997) The anti-phospholipid (Hughes) syndrome: a crossroads of autoimmunity and atherosclerosis. Lupus 6: 559-560. 